\title{
Experimental study of gas breakthrough and emission in an unsaturated clay landfill cover
}

\author{
Z. K. Chen ${ }^{1, a}$, J. L. $\mathrm{Coo}^{1}$ and C. W. W. $\mathrm{Ng}^{1}$ \\ ${ }^{1}$ Department of Civil and Environmental Engineering, Hong Kong University of Science and Technology, HKSAR
}

\begin{abstract}
Decomposition of municipal solid waste (MSW) generates a large amount of landfill gases (LFG) which can pose a high risk to the health of nearby residents and significantly promote global warming when they are released to the atmosphere. A commonly used method to control LFG emission is to place an engineering cover with a gas collection system over MSW. LFG pressure increases in landfill covers when the efficiency of gas collection systems is low, resulting in large gas emissions from cover surface. Compacted clay has been commonly used in landfill cover systems as a hydraulic barrier. However, the effectiveness of compacted clay as a gas barrier, especially resisting gas breakthrough and reducing emission rate under controlled conditions is not fully understood. In this paper, gas breakthrough pressure and emission rate were determined through a one-dimensional (1D) column over a wide range of landfill gas pressures under various degrees of saturation, thicknesses and degrees of compaction. Experiment results show that under a gas pressure of $10 \mathrm{kPa}$, a minimum of $0.4 \mathrm{~m}$ thick clay layer is able to prevent gas breakthrough at degree of saturation of about $60 \%$ (in humid regions). The reduction of gas emission rate by increasing degree of compaction is most prominent in the range of intermediate degree of saturation.
\end{abstract}

\section{Introduction}

Waste decomposition from municipal solid waste (MSW) generates a large amount of landfill gases (LFGs), namely $\mathrm{CO}_{2}$ and $\mathrm{CH}_{4}$. The LFG may emit from the landfill and hence intensify global warming. Although gas collection systems have been proposed to install in the landfill, LFGs cannot be collected completely [1]. To minimize emission of LFG to the atmosphere, a common method to isolate MSWs from the environment is to place an engineered cover over landfills. However, LFG will break through the cover when certain gas pressure is reached $[2,3]$. Compacted clay, due to its relatively low saturated water permeability, has been widely used for landfill final cover systems $[4,5]$. In reality, however, landfill covers are unsaturated in service [6]. Infiltrated rainfall water can only increase their degrees of saturation but it is extremely not likely to saturate them. This means that it would be non-conservative to consider saturated compacted clay for preventing gas since the unsaturated environments favour gas flows than the extreme saturated conditions. The feasibility of unsaturated compacted clays as gas barriers in a landfill cover is thus worthwhile to be explored over a wide range of landfill gas pressures under various degrees of saturation and degrees of compaction.

For the gas breakthrough pressure of clay at ultimate limit state (high gas pressure), water-saturated swelling clay has been widely tested $[7,8]$, due to wide applications of swelling clay in nuclear waste disposal which generally locates hundreds of meters below the ground surface. The measured gas breakthrough pressure of saturated swelling clay is relatively high (in the order of $\mathrm{MPa}$ ). The reported gas pressure may not be applicable to compacted clay in the landfill cover due to several reasons. Firstly, compacted clay in the landfill cover is usually unsaturated. Effects of degree of saturation on gas breakthrough pressure in the context of landfill cover are not understood. Secondly, although LFG pressure may reach $50 \mathrm{kPa}$ at some extreme condition [9], field monitoring results suggest that LFG pressure is typically less than $10 \mathrm{kPa}$ [1]. Compared with gas pressure in nuclear waste disposal, gas pressure in municipal waste landfill is much lower. The huge difference in gas pressure may affect test results.

For the gas emission rate at serviceability limit state (low gas pressure), Moon et al. [10] carried out a series of gas permeability tests on oven-dried clayey soil using a permeameter. Based on measured gas permeability, they concluded that compacted clay may not be sufficient to prevent landfill gas emission. It should be pointed out that there is no standard for gas permeability for designing landfill cover but gas emission rate is considered as an indicator for designing the landfill cover in the available guidelines. For example, Australian guideline [11] allows for a maximum methane emission rate of $63 \mathrm{ml} / \mathrm{m}^{2} / \mathrm{min}$. The gas emission rate should be strongly affected by not only gas permeability of soil, but

\footnotetext{
$\overline{{ }^{a} \text { Corresponding author: zchenam@ }}$ connect.ust.hk
} 
also the thickness, degree of compaction and degree of saturation of soil layer. Moon et al. [10] only tested dry triaxial size soil specimens, which are much smaller than the typical thickness of compacted clay (or fine-grained soil) layer in a landfill (i.e., 0.3 to $1.5 \mathrm{~m}$ ) [12]. To fully understand efficiency of unsaturated compacted clay on limiting gas emission, it is necessary to study effects of clay thickness, degree of compaction and degree of saturation.

In this study, two series of gas breakthrough tests at pressure ranged from 0 to $50 \mathrm{kPa}$ and two series of gas emission rate tests at pressure range of 0 to $20 \mathrm{kPa}$ were carried out on unsaturated compacted Kaolin clay using one-dimensional soil column. Three clay degrees of saturation $(40 \%, 60 \%$ and $80 \%)$, two degrees of compaction $(90 \%$ and $100 \%)$ and two clay thicknesses $(0.4 \mathrm{~m}$ and $0.6 \mathrm{~m})$ were considered.

\section{Experimental program and procedures}

Two types of tests (gas breakthrough test and gas emission rate test) were carried out in this study by using 1-D soil column. The first type of tests was conducted to determine gas breakthrough pressure in unsaturated clay in high gas pressure ranged from 0 to $50 \mathrm{kPa}$. In each test, gas pressure was increased in a stepwise manner at constant time intervals until gas breakthrough occurs. Breakthrough pressure was defined to be the pressure at which the gas flow rate has a dramatic increase. For this test type, two series of tests (BSr and BTh) were conducted to identify gas breakthrough pressures considering three degrees of saturation $\left(\mathrm{S}_{\mathrm{w}}=60 \%, 80 \%\right.$ and $100 \%)$ and two clay thicknesses $(\mathrm{H}=0.4$ and $0.6 \mathrm{~m})$.

The second type of tests was conducted to study the gas emission rate through the unsaturated clay in low gas pressure range of 0 to $20 \mathrm{kPa}$. In each test, constant gas pressure was applied at certain intervals until gas flow rate reaches a stable value. There are also two series of gas emission rate tests ( $\mathrm{CSr}$ and $\mathrm{CTh}$ ) in this study. The objectives of $\mathrm{CSr}$ and $\mathrm{CTh}$ are to investigate influence of degree of saturation, degree of compaction and thickness of unsaturated clay layer on the gas emission rate, respectively. More details of the test program are given in Table 1.

Table 1. Testing program.

\begin{tabular}{|c|c|c|c|c|}
\hline $\begin{array}{c}\text { Test } \\
\text { series }\end{array}$ & $\begin{array}{c}\text { Degree of } \\
\text { saturation } \\
\text { at } \\
\text { compaction } \\
\boldsymbol{S}_{w}(\mathbf{\%})\end{array}$ & $\begin{array}{c}\text { Thickness } \\
\boldsymbol{H}(\mathbf{m})\end{array}$ & $\begin{array}{c}\text { Degree of } \\
\text { compaction } \\
\text { DOC (\%) }\end{array}$ & $\begin{array}{c}\text { Gas } \\
\text { pressure } \\
\mathbf{P}_{\mathbf{g}}(\mathbf{k P a})\end{array}$ \\
\hline $\mathrm{BSr}$ & $60,80,100$ & 0.4 & 100 & $0 \sim 50$ \\
\hline $\mathrm{BTh}$ & 80 & 0.6 & 100 & $0 \sim 50$ \\
\hline $\mathrm{CSr}$ & $40,60,80$ & 0.4 & 90,100 & $\begin{array}{c}1,5,10, \\
20\end{array}$ \\
\hline $\mathrm{CTh}$ & $40,60,80$ & 0.6 & 90,100 & $\begin{array}{c}1,5,10, \\
20\end{array}$ \\
\hline
\end{tabular}


respectively. EC-5 water content sensors were installed at the same elevation with pore air pressure transducers to measure soil volumetric water content. Furthermore, depending on gas emission rate in each test, two types of gas flow meter with different measuring ranges ( 0 to 100 $\mathrm{ml} / \mathrm{min}$ and 0 to $30 \mathrm{~L} / \mathrm{min}$ ) and accuracies $(0.5 \mathrm{ml} / \mathrm{min}$ and $5 \mathrm{ml} / \mathrm{min}$ ) were considered and used in this study. When high gas emission is expected, the one with wider measuring range is chosen. Otherwise, the one with narrower measuring range but higher accuracy is used. Prior to each test, all transducers were carefully calibrated.

\subsection{Testing material}

The test soil in this study is Kaolin clay. Some basic properties including Atterberg limits, specific gravity, compaction curve, water saturated permeability of the soil were determined following ASTM standard test methods $[14,15,16,17]$. The test results are summarized in Table 2 [2]. Figure 2 shows water retention curve (WRC) of the compacted clay during the drying process from fully saturated state. It was measured using a modified pressure plate apparatus [18]. From the relationship between volumetric water content and suction, air-entry value of the compacted clay is estimated to be about $70 \mathrm{kPa}$. Furthermore, the measured WRC was fitted using van Genuchten's equation [19]:

$$
\theta_{w}=\theta_{r}+\left(\theta_{s}-\theta_{r}\right)\left[1+(s / a)^{n}\right]^{-m}
$$

where $\theta_{w}$ is the volumetric water content of unsaturated soil; $\theta_{s}$ is the saturated volumetric water content; $\theta_{r}$ is the residual volumetric water content; $s$ is soil suction $(\mathrm{kPa}) ; a$ is a parameter related to the air-entry value of soil $(\mathrm{kPa}) ; n$ and $m$ are fitting parameters related to the shape of WRC. According to van Genuchten [19], the parameter $m$ was simplified to be $(1-1 / n)$ in the fitting process to reduce the number of model parameters. In this study, two methods were used to prepare soil samples, depending on their degree of saturation. For the tests at degrees of saturation of $40 \%, 60 \%$ and $80 \%$, oven-dried soil was initially mixed with de-aired water to reach the targeted water content. The mixed soil was then placed in a temperature and humidity controlled room for $48 \mathrm{~h}$ for moisture homogeneity. After that, each sample $(140 \mathrm{~mm}$ in diameter and $400 / 600 \mathrm{~mm}$ in height) was dynamically compacted in 20 sub-layers.

To achieve desired degree of compaction, 15 hammer drops was required for each sub-layer. It should be pointed out that a thin layer of vacuum grease was placed on the inner surface of soil column to minimize preferential flow paths along the gap between soil and the sidewall of soil column.

For the tests at degree of saturation of $100 \%$, soil samples were firstly prepared at the optimum water content which is equivalent to degree of saturation of $80 \%$, following the methods described above. Then, each sample was subjected to bottom-up saturation to achieve degree of saturation of about $100 \%$. All the soil samples were allowed to equalize after preparation.
Table 2. Basic properties of the soil.

\begin{tabular}{lc}
\hline Property & Value \\
\hline Unified soil classification system & $\mathrm{CH}$ \\
Specific gravity & 2.52 \\
Liquid limit (\%) & 59 \\
Plastic limit (\%) & 32 \\
Plasticity Index (\%) & 27 \\
Maximum dry density $\left(\mathrm{kg} / \mathrm{m}^{3}\right)$ & 1264 \\
Optimum moisture content $(\%)$ & 36.18 \\
Saturated water coefficient of permeability $(\mathrm{m} / \mathrm{s})$ & $5.2 \times 10^{-9}$ \\
Water content at saturation $(\%)$ & 42.06 \\
\hline
\end{tabular}

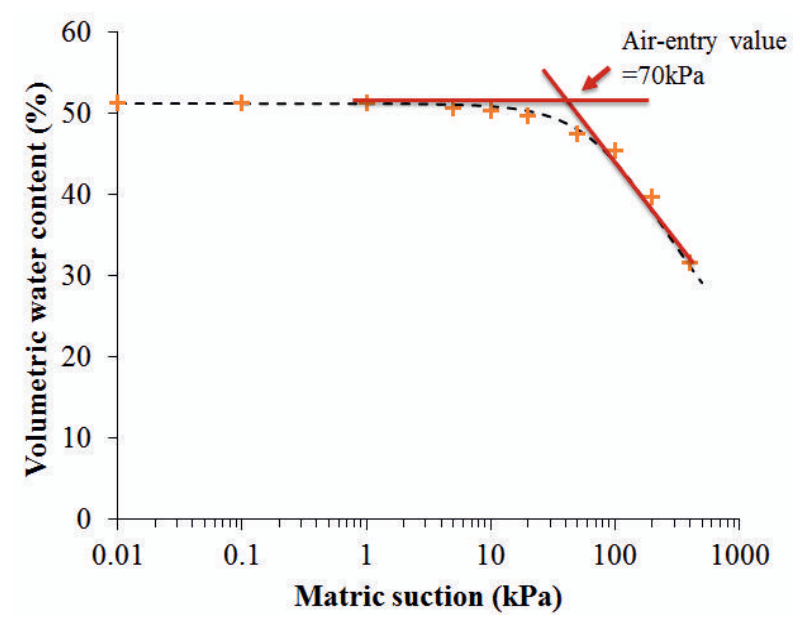

Figure 2. Measured and fitted WRC.

\subsection{Testing procedures}

For the gas breakthrough tests (series BSr and BTh), after soil preparation, a constant gas pressure of $5 \mathrm{kPa}$ was applied at the base of soil sample for 3 days. If no gas breakthrough occurs, gas pressure was increases from 5 to $10 \mathrm{kPa}$ and then maintained at constant value for another 3 days. Then, gas pressures of 15, 20, 30, 40 and $50 \mathrm{kPa}$ were subsequently applied to soil sample until gas breakthrough occurs.

For the gas emission rate tests (series CSr and CTh), after soil preparation, constant gas pressures were applied at the bottom of soil until a stable gas flow is achieved. When the stage at gas pressure of $1 \mathrm{kPa}$ was finished, the gas pressure was increased to $5 \mathrm{kPa}$ and then kept constant until a stable gas flow is achieved. Then, 10 and $20 \mathrm{kPa}$ gas pressures were applied by following a similar procedure.

During the tests, pore air pressure distributions were measured using pore air pressure transducers along the depth of soil column. Water content and density of soil samples were checked before each test to ensure the desired degree of saturation was reached. Gas emission rate was monitored at the top of soil sample using a flow meter. Furthermore, all tests were conducted in a 
temperature-controlled room $\left(20 \pm 1^{\circ} \mathrm{C}\right)$ where density and viscosity of gas were considered to be constant.

\section{Results and discussion}

\subsection{Gas breakthrough pressure at different degrees of saturation}

Figure 3 shows the relationship between applied gas pressure and gas emission rate at three different clay degrees of saturation $\left(\mathrm{S}_{\mathrm{w}}=60 \%, 80 \%\right.$ and $\left.100 \%\right)$. The figure clearly reveals two types of soil response. At degree of saturation of $60 \%$ and $80 \%$, the gas emission rate is almost zero in the lower range of gas pressure. When the gas pressure reaches a threshold value, the gas emission rate suddenly increases. According to the definition of gas breakthrough pressure mentioned, it can be seen from the figure that gas breakthrough pressure is estimated to be 22 and $38 \mathrm{kPa}$ at degree of saturation of $60 \%$ and $80 \%$, respectively. On the other hand, for the test at degree of saturation of $100 \%$, gas emission rate is almost zero in the whole range of gas pressure $(0-50$ $\mathrm{kPa}$ ). This suggests that gas breakthrough pressure is higher than $50 \mathrm{kPa}$ at this testing condition. Comparisons between the three curves illustrate that the gas breakthrough pressure increases with increasing degree of saturation. The influence of degree of saturation is most likely because more pores are occupied by soil water in the compacted sample at higher degree of saturation. A higher pressure is therefore required to form an interconnected air-filled channel for gas flow.

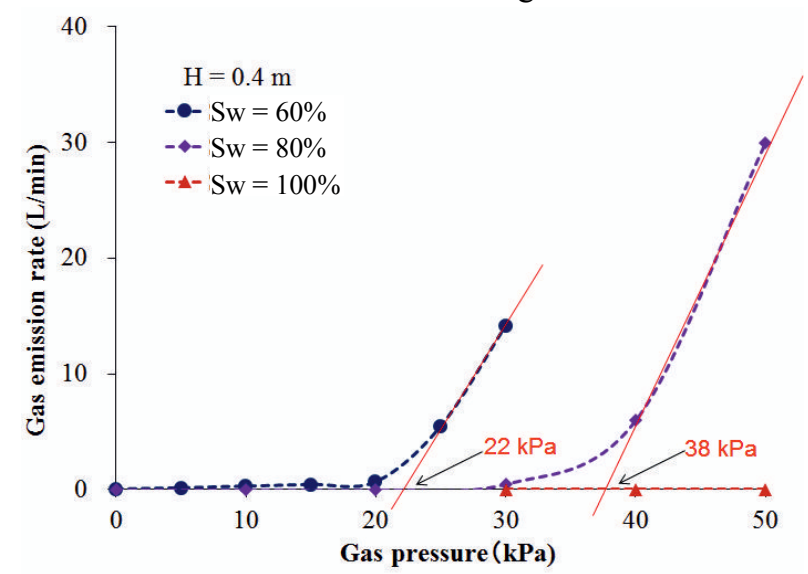

Figure 3. Gas breakthrough pressure at different degrees of saturation.

Based on field measurements, McBean et al. [1] reported that landfill gas pressure in the field is generally less than $10 \mathrm{kPa}$. Under typical landfill gas pressures, compacted clay layer with thickness of $0.4 \mathrm{~m}$ or above is able to prevent gas breakthrough when clay degree of saturation is larger than $60 \%$, as illustrated in Figure 6. This finding suggests that in humid regions where soil degree of saturation is generally larger than $60 \%$ [6], a $0.4 \mathrm{~m}$-thick clay layer is sufficient to satisfy design requirements at ultimate limit state.

\subsection{Influence of clay thickness on gas breakthrough pressure}

Figure 4 shows results of gas breakthrough tests at two clay thicknesses $(\mathrm{H}=0.4$ and $0.6 \mathrm{~m})$. Gas breakthrough pressure of about $38 \mathrm{kPa}$ was estimated for $0.4 \mathrm{~m}$-thick clay. When the clay thickness increases to $0.6 \mathrm{~m}$, the gas emission rate still remains almost zero even for gas pressure up to $50 \mathrm{kPa}$. This suggests that the gas breakthrough pressure can be higher than $50 \mathrm{kPa}$ for a 0.6 $\mathrm{m}$-thick clay layer. The observed increase of gas breakthrough pressure with increasing clay thickness is mainly because as clay thickness increases, the possibility of forming interconnected air-filled flow paths along the whole sample depth decreases. Similar observations have been reported by Hildenbrand et al. [8]. Based on the tests in a limited range of sample thickness (less than $0.03 \mathrm{~m}$ ), they also found that gas breakthrough pressure increases as soil thickness increases under same gas pressure. These results suggest that the capacity of compacted clay to prevent gas breakthrough can be significantly improved by increasing clay thickness. According to the results in Figure 3 and Figure 4, in arid regions where soil degree of saturation may drop below $60 \%$, a $0.4 \mathrm{~m}$-thick clay layer may fail to prevent the occurrence of gas breakthrough. One possible solution to this problem is to increase the thickness of clay layer in the landfill cover.

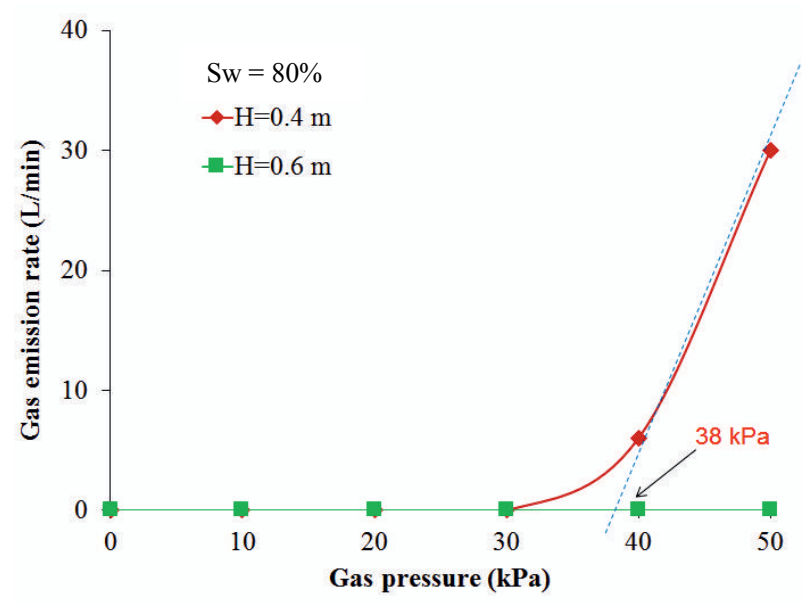

Figure 4. Effect of clay thickness on gas breakthrough pressure.

\subsection{Gas emission rates at different degrees of compaction and degrees of saturation}

Figure 5 shows the relationship between gas emission rate and gas pressure at two degrees of compaction $(90 \%$ and $100 \%)$ and three degrees of saturation $(40 \%, 60 \%$ and $80 \%$ ). For $40 \%$ and $60 \%$ degrees of saturation, as expected, gas emission rate increases with an increase of gas pressure for both degrees of compaction. This is because the gas pressure increases induce a continuous increase of gas emission rate with increasing pressure gradient. For degree of saturation of $80 \%$, gas emission rate was almost zero even for gas pressure up to $20 \mathrm{kPa}$ for both degrees of compaction. This is consistent with the result of gas breakthrough tests. As illustrated in Figure 3, the gas breakthrough pressure at degree of 
saturation of $80 \%$ is up to $38 \mathrm{kPa}$ and gas emission rate is almost negligible at gas pressures less than $20 \mathrm{kPa}$. Furthermore, the effect of degree of compaction on gas emission rate is also illustrated in the figure. At low degree of saturation (i.e., 40\%), gas emission rate for $90 \%$ degree of compaction is similar to that of $100 \%$ degree of compaction within the whole applied gas pressure range $(0 \sim 20 \mathrm{kPa})$. When the degree of saturation increases up to $60 \%$, the effect of degree of compaction on gas emission rate is distinct. For a given gas pressure (i.e., $10 \mathrm{kPa}$ ), gas emission rate can be reduced by $65 \%$ when the degree of compaction increases from $90 \%$ to $100 \%$ under a soil degree of saturation of $60 \%$. This may be due to the aggregation effect of compacted clay. During compaction, soil aggregates are much easier to compress at a relatively high initial degree of saturation than a low initial degree of saturation. When the degree of saturation further increases up to $80 \%$, gas emission rate obtained from both degrees of compaction becomes almost zero. This is because more clay aggregates at this high degree of saturation are compressed compared to the intermediate degree of saturation (i.e., 60\%) and low degree of saturation (i.e., 40\%). Comparisons between the six curves (corresponding to degree of saturation of $40 \%, 60 \%$ and $80 \%$ and two degrees of compaction of $90 \%$ and $100 \%$ ) clearly reveal that at the same gas pressure, gas emission rate is significantly lower at higher degree of saturation. This is because a higher degree of saturation induces smaller gas permeability and thus lower gas emission rate. The effect of degree of compaction on reducing gas emission rate dominates only in relatively high degree of saturation due to the clay aggregation effect.

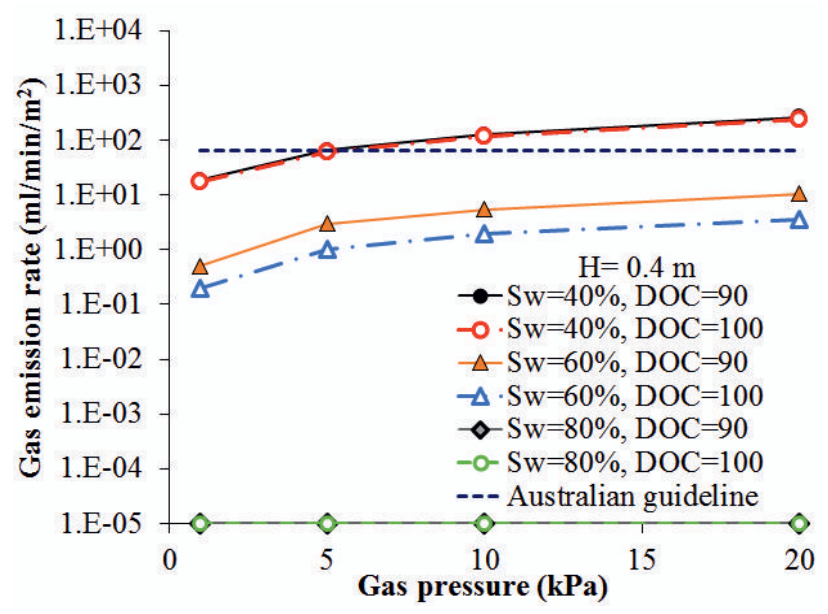

Figure 5. Gas emission rate at different degrees of compaction and degrees of saturation $(\mathrm{H}=0.4 \mathrm{~m})$.

In the figure, methane emission limit proposed by the Australian government guideline [11] is also included for comparison. According to this guideline, methane emission rate in a landfill should be less than 63 $\mathrm{ml} / \mathrm{m}^{2} / \mathrm{min}$. To meet the requirement of the gas emission rate limit set by the Australian guideline, a clay layer with thickness of $0.4 \mathrm{~m}$ at degree of saturation of $60 \%$ and $80 \%$ is sufficient in the range of typical landfill gas pressure (less than $10 \mathrm{kPa}$ ) observed in field [1].
However, at degree of saturation of $40 \%$, a 0.4 m-thick clay layer is sufficient only if the gas pressure is less than $5 \mathrm{kPa}$. A possible solution to this problem is to increase the thickness of clay layer. More discussions of effects of clay thickness are given later. It should be pointed out that although this guideline is proposed for methane emission, it should be applicable to some other gases (such as $\mathrm{N}_{2}$ ). This is because the physical properties including viscosity of methane and nitrogen are similar.

\subsection{Influence of clay thickness on gas emission rate}

Figure 6 shows the gas emission rate corresponding to the gas pressure applied. Three degrees of saturation $(40 \%$, $60 \%$ and $80 \%)$ and two degrees of compaction $(90 \%$ and $100 \%$ ) were considered. The clay thickness used herein is $0.6 \mathrm{~m}$. As expected, gas emission rate increases with increasing gas pressure and decreasing degree of saturation. Similar phenomena was observed as compared with Figure 5. Clay degree of compaction has prominent effect on reducing gas emission rate only in the intermediate degree of saturation (i.e., 60\%). For example, at a given gas pressure (i.e., $10 \mathrm{kPa}$ ), 75\% increment for gas emission rate was observed when the degree of compaction increase from $90 \%$ to $100 \%$ under a soil degree of saturation of $60 \%$. As compared with the maximum gas emission rate allowed by Australian guideline [11], when clay thickness increase up to $0.6 \mathrm{~m}$, the gas emission limit can be met under a gas pressure of less than $10 \mathrm{kPa}$. Comparison between this figure and Figure 5 clearly demonstrated that gas emission rate decreases significantly with an increase of clay thickness.

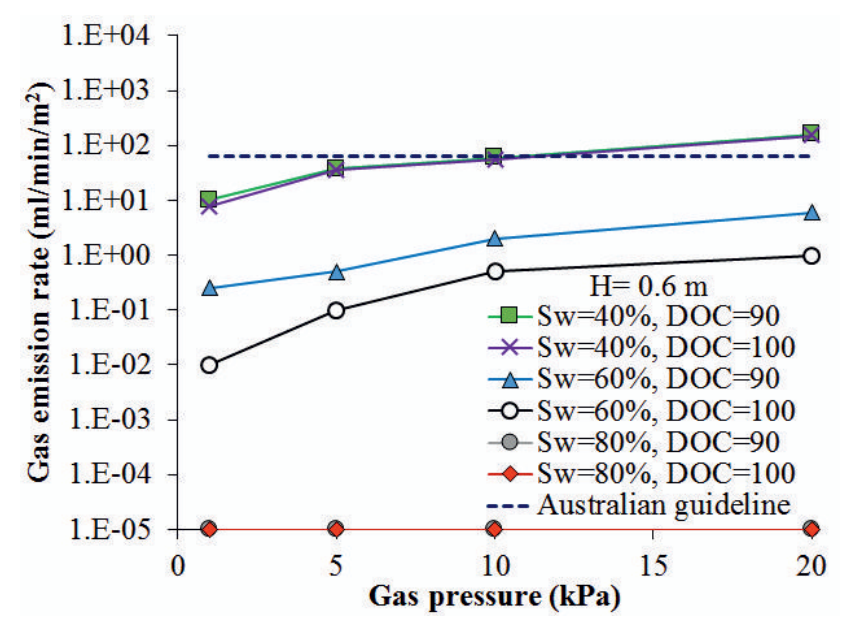

Figure 6. Effect of clay thickness on gas emission rate $(\mathrm{H}=0.6 \mathrm{~m})$.

To meet the requirement of the gas emission rate limit set by the Australian guideline, landfill designer should locate the clay layer at the bottom of landfill cover to eliminate moisture loss. Moreover, a thicker clay layer should be adopted in relatively arid area in order to minimize gas emission rate. 


\section{Conclusions}

Gas breakthrough pressures and gas emission rates of unsaturated compacted clay were measured at different degrees of saturation and soil thicknesses. Gas breakthrough pressure of unsaturated compacted clay increases as the degree of saturation and thickness of clay increase. Under a gas pressure of $10 \mathrm{kPa}$ (the upper bound limit of typical landfill gas pressure), a minimum of $0.4 \mathrm{~m}$ thick clay layer is able to prevent gas breakthrough at degree of saturation of about $60 \%$ or higher (in humid regions). A thicker clay layer is required if clay degree of saturation is lower than $60 \%$. The reduction of gas emission rate by an increase in the degree of compaction is remarkable only in the range of intermediate degree of saturation. For low degree of saturation (i.e., 40\%), degree of compaction has almost no influence on gas emission in the gas pressure range from 0 to $20 \mathrm{kPa}$.

\section{Acknowledgements}

The authors would like to acknowledge the research grant (2012CB719805) from the National Basic Research Program (973 Program) provided by the Ministry of Science and Technology of the People's Republic of China and research grant (HKUST6/CRF/12R) provided by the Research Grants Council (RGC) of the Hong Kong Special Administrative Region.

\section{References}

1. E. A. McBean, F. A. Rovers, G. J. Farquhar, Solid Waste Landfill Engineering and Design (Prentice Hall PTR, Englewood Cliffs, 1995)

2. C. W. W. Ng, Z. K. Chen, J. L. Coo, R. Chen \& C. Zhou, Waste Manag. 44, 155-163 (2015)

3. C. W. W. Ng, J. Xu, and R. Chen, U.S. Patent No. 9,101,968 B2 (2015)

4. C. H. Benson, M. A. Barlaz, D. T. Lane, J. M. Rawe, Waste Manag. 27, 1, 13-29 (2007)

5. K. D. Barnswell, D. F. Dwyer, Waste Manag. 32, 12, 2336-2341 (2012)

6. G. Zhan, J. Keller, M. Milczarek, J. Giraudo, Mine Water Environ. 33, 195-205 (2014)

7. J. F. Harrington, S. T. Horseman, Swedish Nuclear Fuel and Waste Management Company, Stockholm (Sweden) (2003)

8. A. Hildenbrand, S. Schlomer, B. M. Krooss, Geofluids 2, 1, 3-23 (2002)

9. H. Y. Wei, Ph.D. dissertation, Zhejiang University, Hangzhou, China (in Chinese) (2007)

10. S. Moon, K. Nam, J. Y. Kim, S. K. Hwan, M. Chung, Waste manag. 28, 10, 1909-1914 (2008)

11. Carbon Farming Initiative, Guidelines for calculating regulatory baselines for legacy waste landfill methane projects, Australian Government (2013)

12. EPA, U.S. Research Triangle Park, NC. EPA453R/96-004 (1999)

13. A. Bouazza, T. Vangpaisal, Geotext. Geomembranes 21, 2, 85-101 (2003)
14. ASTM, D4318, West Conshohocken, PA (2010)

15. ASTM, D2487, West Conshohocken, PA (2011)

16. ASTM, D698, West Conshohocken, PA (2012)

17. ASTM, D5084, West Conshohocken, PA (2010)

18. C. W. W. Ng, Y. W. Pang, J. Geotech. Geoenviron. Eng. ASCE 126, 2, 157-166 (2000)

19. M.T. van Genuchten. Soil Sci. Soc. Am. J. 44, 5, 892-898 (1980) 